ICAASET-2021, 20-21 May, 2021, K.R. Mangalam University, Gurugram

International Journal of Technical Research \& Science (Special Issue) ISSN No.:2454-2024 (online)

\title{
REVIEW ON COMPARATIVE STUDY FOR REMOVAL OF ORGANIC POLLUTANTS USING DIFFERENT FORMS OF GRAPHENE OXIDE
}

Preeti Rawat, Meena Bhandari, Neeraj Kumari

E-Mail Id: meena.bhandari@krmangalam.edu.in, neeraj.kumari@krmangalam.edu.in

School of Basic and Applied Science, K.R. Mangalam University, Gurgaon, Haryana, India

Abstract- Textile wastewater due to the presence of dyes effluents has become a severe environmental problem worldwide and has reached on alarming stage. Therefore, from past few decades, different practices have been used by researchers and scientist to eliminate these effluents. Among them, adsorption is one most effective method due to its low cost, ease availability and handling. Recently, graphene oxide and its composites are gaining a lot of attention for removing not only dye effluents but other contaminants also. The present review reveals the importance of graphene oxide and their composites to eliminate dyes affluents from waterbodies along with classification of dyes and different adsorption techniques.

Keywords: Dye effluents, Adsorption, Graphene oxides, Textile wastewater.

\section{INTRODUCTION}

In $21^{\text {st }}$ century, the major problem faced by the world is water pollution which is due to the rapidly growing industrialization, urbanization results in creating huge stress on use of water. The major contributor of water pollution is wastewater effluents such as dyes, heavy metals, pesticides, drugs etc. Among air, soil, noise and water pollution, water pollution is major problem as water has capacity to dissolve most of the substance as compared to any other liquid present on the earth [1]. Moreover, the resources of water like oceans, rivers, lakes and ponds are flooding with plastics, chemicals, dyes and other toxic pollutants which also cause water pollution. The environment and human health are both impacted in the short and long term when untreated and poorly handled wastewater is discharged into waterways. As a result, to protect the health of residents of both rural and urban areas, environmental rules related to water pollution should be strictly enforced. According to World Water Council report, there will be around 3.9 billion peoples by 2030 who are living in water scare areas [2]. Due to water shortage, it is very necessary to treat wastewater which fit for household, manufacturing, and agricultural activities. Textile processing is a huge industry that produces a lot of wastewater all over the world. Therefore, the management of wastewater and purification of potable water are important for the rapid progress of human society while also reducing contamination and health risks.

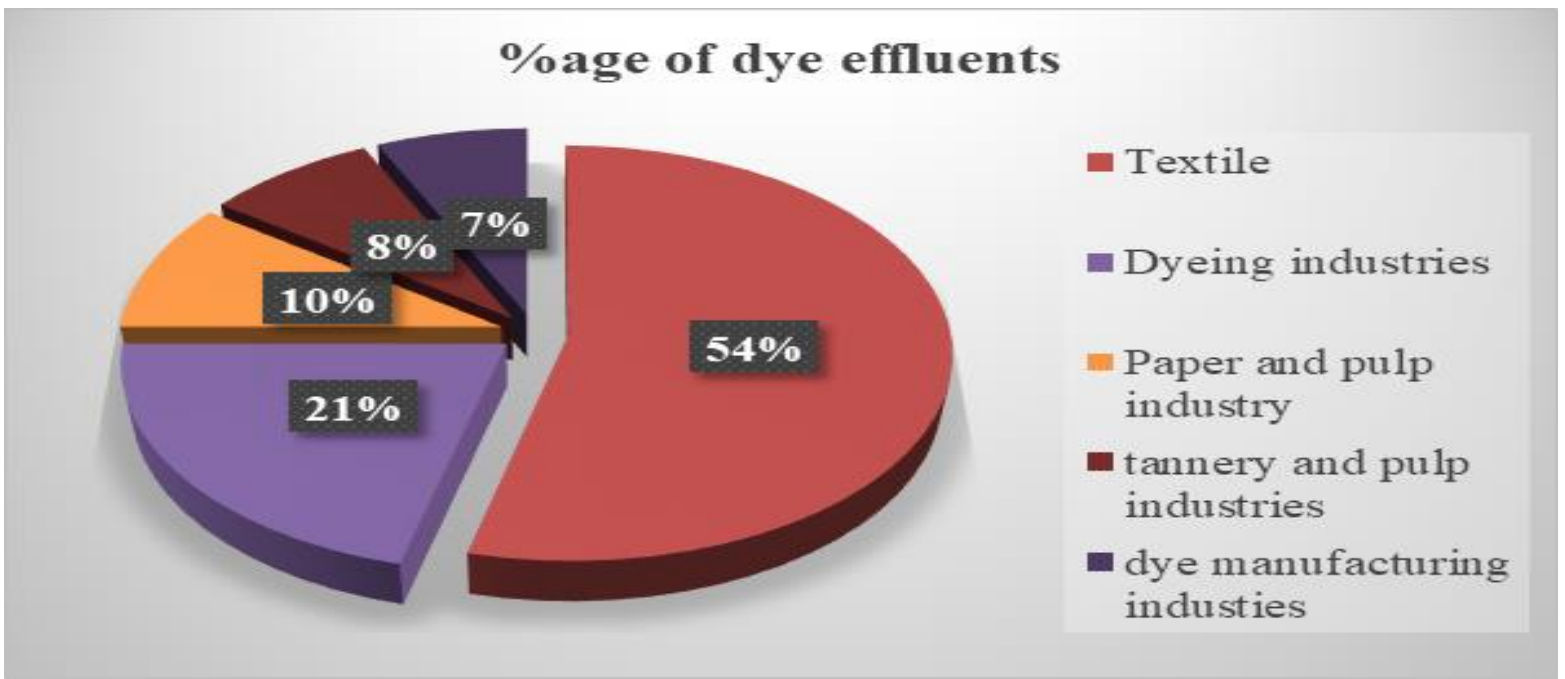

Fig. 1.1 Discharge of dye effluents from various industries

In India's major cities, approximate 38354 million litres per day (MLD) of sewage is produced, but their treatment is only 11786 MLD. Similarly, the treatment of industrial wastewater originated mainly from large-scale factories is only $60 \%$ [3]. In this situation, wastewater treatment has become foremost important. The industries like textile, paper and pulp, dye and dye intermediates, paint, pharmaceutical and tannery etc. discharge the organic contaminants into natural water supplies. Among all industries, textile industry produced more than half of all dye effluents (54\%) as shown in Figure 1 [4], [5].

All over the world, approximate 10,000 types of textile dyes are generated based on color index and $7 \times 10^{5}$ tons of dyes are produced. The major countries have a major role in textile industries are China, United States, Pakistan, Brazil, Taiwan, Turkey, Bangladesh including India. Among all countries, India is largest textile producer where different types of raw materials like synthetic fibers, cellulose fibers are used [6]. According to a study, almost 1.6 million liters water is used by textile industries per day for the production of $8000 \mathrm{~kg}$ fabric where $16 \%$ of that water utilized to dye the clothes and $8 \%$ for printing as shown in Figure 2 [5]. 
ICAASET-2021, 20-21 May, 2020, K.R. Mangalam University, Gurugram

International Journal of Technical Research \& Science (Special Issue) ISSN No.:2454-2024 (online)

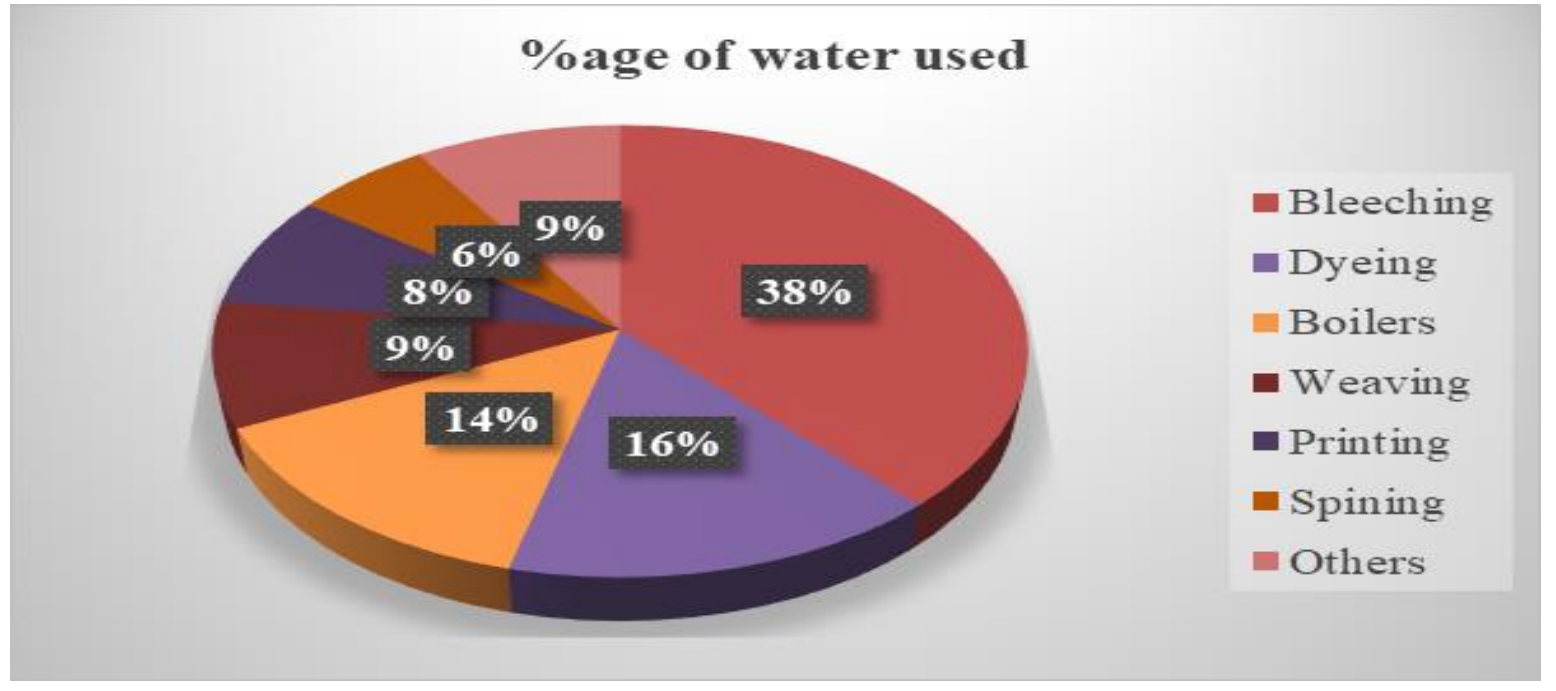

Fig. 1.2 Textile processing consuming water

The chemical processes in textile industries includes bleaching and dyeing which generates a large quantity of effluent containing a large volume of substantial contaminants such as higher chemical oxygen demand (COD), biological oxygen demand (BOD), dispersant, levelling agents, nitrogen, carriers, salts, heavy metals traces, dispersants, acids, alkali, and different types of synthetic dyes [7].

\section{INDUSTRIAL DYE MATERIALS}

A very common classification of the dyestuff used in textile industries is based on the source from which it is made. The most classification of dyes is done on the basis of their source from where they are originated: natural and synthetic. The synthetic dyes are further categorized into two categories: water insoluble and water-soluble dyes [8].

The most common dyes used in textile industries are acidic and basic dyes due to their bright colour, high solubility in water, low cost, and being simpler to apply to fabrics. As a result, discharge of contaminants spreads toxicity, degrades water quality and have a serious impact on photosynthesis process. Furthermore, due to low light penetration and inadequate oxygen intake, it has a major effect on the aquatic environment. The studies also revealed about genotoxicity and carcinogenic nature of dyes. They can cause various kinds of diseases like bladder cancer, dermatitis, kidney disorder after entering into skin through inhalation, ingestion or skin pores.

Therefore, effluents must be properly treated before being discharged results in enhancement of alternative of water reusability. By 2030, the United Nations has set a goal to enhance "water quality by removing pollutants, eliminating disposal, and reducing the discharge of toxic chemicals and products, percentage of contaminated water results in significantly improving recycling and reuse of water". The environmental technology market of India is also booming, with plenty of business prospects for pollution-reduction technology developments [1].

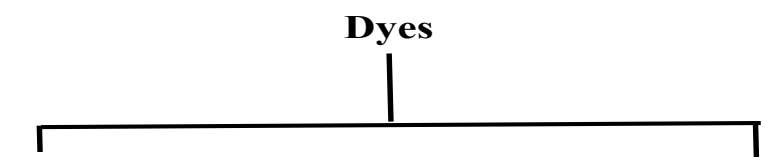

Natural

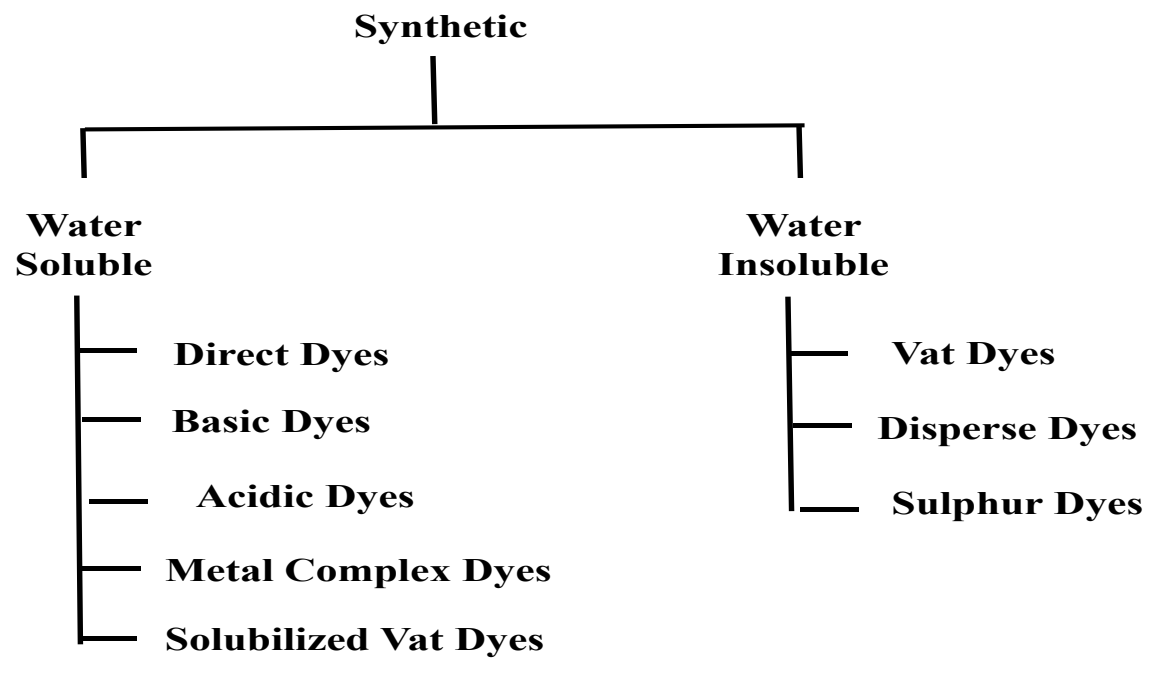

Fig. 2.1 Classification of dyes 
ICAASET-2021, 20-21 May, 2020, K.R. Mangalam University, Gurugram

International Journal of Technical Research \& Science (Special Issue) ISSN No.:2454-2024 (online)

\section{TECHNIQUES USED FOR REMOVING DYES FROM WATER BODIES}

From past few decades, different techniques such as ion exchange, membrane separation, coagulation/ flocculation, photodegradation, charcoal filtration, reverse osmosis, ultra-filtration and some biological methods are used for removal of dyes on a large scale. There are some drawbacks of these methods like consumption of high energy, complex design and extended operation times due to which these methods can not be afforded by textile industries especially in developing countries like India [9].

Therefore, one of the most suitable and effective method for eliminating of the dyes from discarded water is adsorption as it is cost-effective with flexible design, more availability, and high energy efficient. Generally, adsorption is a surface process in which the pollutants adhered onto adsorbent's surface [10].

Adsorption is a unit procedure used to separate contaminants from industrial wastewater. Adsorbents used for elimination of dyes are zeolite, charcoal, naturally occurring clay minerals, fly ash, chitosan, fruit waste, rice husk, scrap tyres, petroleum waste, metal nanoparticles, graphene oxides etc [11].

Among all the adsorbents, graphene oxide is known as promising adsorbent to adsorb dyes effluents from water bodies. As graphene has high theoretical specific surface area, high negative charge density, it is largely used for removal of contaminants. The surface of graphene oxide is hydrophobic due to the delocalized $\pi$-electron system which provide stability to graphite over other adsorbents. They are also easily synthesized using exfoliation/ chemical oxidation method on large scale from abundant natural graphite [12].

The purpose of the review is to study current state of graphene oxide and their composites to remove the dyes from water bodies. The review also focusses on adsorption efficiency of graphene-based composites and mechanisms for removing the dyes with their regeneration.

\section{DYES REMOVAL USING DIFFERENT FORMS OF GRAPHENE OXIDE}

Different types of dyes present in water bodies are harmful not only for aquatic life but for human being and environment also results in raising the global concern. Graphene oxides and its composites are known as one of the most effective adsorbents to remove the dye effluents like methylene blue, crystal violet, rhodamine-G, indigo carmine etc. with much higher adsorption capacities than other adsorbents.

Methyl orange and basic red 12 were removed by applying graphene oxide from wastewater. $6.83 \mathrm{mg} / \mathrm{g}$ of methyl orange and $63.69 \mathrm{mg} / \mathrm{g}$ for basic red 12 dye adsorb onto graphene oxide within 100 minutes of contact time at $\mathrm{pH}$ 3 of the media. The adsorption efficiency of graphene oxide was more for basic red 12 due to electrostatic interaction between them whereas repulsion was observed between methyl orange and graphene oxide due to having same negative charge. The endothermic nature of the adsorption process was revealed by the effect of temperature [13].

Sharma et al. (2013) employed graphene oxide efficiency to remove methyl green (MG) from aqueous media. $5.496 \mathrm{mmol} / \mathrm{g}$ uptake of dye was recorded at $\mathrm{pH} 5$ which is further confirmed from Langmuir adsorption isotherm. Furthermore, enhancement in the adsorption of dye onto graphene oxide was observed with increase in temperature [14].

Magnetic graphene oxide functionalized with Xanthate groups $\left(\mathrm{Fe}_{3} \mathrm{O}_{4}-\mathrm{xGO}\right)$ were synthesized by Cui et al, (2015) where xanthate groups are linked to graphene magnetic material $\left(\mathrm{Fe}_{3} \mathrm{O}_{4}-\mathrm{GS}\right)$. The synthesized composite showed adsorption efficiency for $\mathrm{Hg}^{2+} 118.55 \mathrm{mg} / \mathrm{g}$ within 180 minutes of contact time at $\mathrm{pH} 7$ and $526.32 \mathrm{mg} / \mathrm{g}$ for methylene blue within 120 minutes at $\mathrm{pH} 5.5$ respectively. The adsorption process was endothermic and spontaneous as confirmed from the thermodynamic studies $(\Delta \mathrm{G}<0, \Delta \mathrm{H}>0, \Delta \mathrm{S}>0)$ [15].

Polydopamine functionalized GO was synthesized by self - polymerization process to remove several dyes like methylene blue (MB), methyl orange (MO), methyl violet (MV), basic fuchsin (BF), Coomassie brilliant blue (CBB), rhodamine B (RHB), malachite green oxalate (MGO) and neutral red (NR) and toxic ions like $\mathrm{Pb}(\mathrm{II})$, $\mathrm{Cu}(\mathrm{II}), \mathrm{Cd}(\mathrm{II})$ and $\mathrm{Hg}(\mathrm{II})$. According to Langmuir adsorption isotherm, maximum removal efficiency of PDA functionalized graphene oxide (15\% polydopamine $-\mathrm{GO}$ ) was $2.181 \mathrm{mg} / \mathrm{g}$ for methylene blue dye which was ten times higher as compared to individual polydopamine or GO [16].

The hydrogel of graphene oxide and chitosan (GO-CS) were synthesized using graphene oxide suspension with Chitosan solution and used for elimination of both methylene blue, a cationic dye and Eosin Y, anionic dye from aqueous media. The efficiency to adsorb both cationic and anionic dyes $(>300 \mathrm{mg} / \mathrm{g})$ was higher for both hydrogels due to their porous structure. The adsorption efficiency varies with change in the composition of hydrogels. As the concentration of GO increased, methylene blue dye adsorption was more and on increasing the concentration of chitosan, Eosin Y adsorption was high which is due to the electrostatic interaction as GO shows negative charge on its surface and chitosan have positive charge respectively for different cationic and anionic dyes [17].

A simple sol gel method developed for synthesis of graphene oxide/ cellulose beads composites to remove cationic dye, Malachite green from water bodies. The results showed over $96 \%$ dye removal (Zhang et al, 2015). Dye adsorption increased on increasing amount of composite beads. These composites beads can be reused for five time more through simple filtration process [18].

Sheng et al. (2016) synthesized a novel adsorbent based on graphene oxide using chitosan, fly ash and graphene oxide where cross-linking of fly ash was with both GO and chitosan takes place. The synthesized adsorbent used for removal of both cationic (Acid Red R) (38.87 mg/g) and anionic dye (Red X-5GN) (64.50 mg/g) [19].

Rong et al, (2015) revealed the adsorption efficiencies of NiO/graphene nanosheets against Congo red, an acidic dye. The nanosheets which are fabricated through hydrothermal method showed $99.56 \%$ uptake of dye in 180 minutes using $1.0 \%$ adsorbent dose of dye concentration e at room temperature. Further, they explained the 
ICAASET-2021, 20-21 May, 2020, K.R. Mangalam University, Gurugram

International Journal of Technical Research \& Science (Special Issue) ISSN No.:2454-2024 (online) adsorption mechanism through isotherm and kinetic model where the equilibrium data fitted well in pseudosecond order kinetic model and Redlich-Peterson model [20].

Table-4.1 Adsorption of various dyes using different forms of graphene oxide

\begin{tabular}{|c|c|c|c|c|}
\hline Adsorbent & Dye & Results & $\begin{array}{c}\text { Isotherm and } \\
\text { Kinetic model }\end{array}$ & References \\
\hline $\begin{array}{l}\text { Graphene oxide (GO), } \\
\text { fluorinated graphene } \\
\text { oxide (F-GO) and } \\
\text { interconnected reduced } \\
\text { graphene oxide (IC-rGO) }\end{array}$ & $\begin{array}{l}\text { Methylene } \\
\text { blue (MB) and } \\
\text { Rhodamine B } \\
\quad(\mathrm{RhB})\end{array}$ & $\begin{array}{c}\text { Adsorption } \\
\text { isotherm revealed } \\
\text { high value of qe at } \\
\text { any Ce for GO. } \\
403.3 \mathrm{mg} / \mathrm{g} \text { for } \\
\mathrm{MB} \\
686.6 \mathrm{mg} / \mathrm{g} \text { for } \\
\text { RhB for GO. } \\
\text { F-GO: The } \\
\text { removal efficiency } \\
\text { was below } 95.1 \% \text { at } \\
120 \mathrm{mg} / \mathrm{L} \text { initial } \\
\text { concentration. } \\
\text { ICrGO: } 47.6 \% \\
\text { removal } \\
\text { efficiency for } \\
\text { both dyes }\end{array}$ & $\begin{array}{c}\text { Langmuir and } \\
\text { Pseudo-second order } \\
\text { kinetic model }\end{array}$ & [10] \\
\hline $\begin{array}{l}\text { Graphene oxide }(\mathrm{GO})- \\
\text { based polymer } \\
\text { nanocomposites (GO- } \\
\text { PDA-PSPSH) }\end{array}$ & $\begin{array}{l}\text { Methylene } \\
\text { blue }\end{array}$ & $\begin{array}{l}279.57 \mathrm{mg} / \mathrm{g} \text { in } 58 \\
\text { minutes at } \mathrm{pH} 7\end{array}$ & $\begin{array}{l}\text { Langmuir and } \\
\text { Pseudo-second order } \\
\text { kinetic model }\end{array}$ & [21] \\
\hline $\begin{array}{c}\text { Graphene oxide } \\
\text { (GO)/poly(N- } \\
\text { isopropylacrylamide) } \\
\text { (PNIPAM) }\end{array}$ & Rhodamine B & $\begin{array}{c}\text { GO: } 610,412 \text { and } \\
223 \mathrm{mg} / \mathrm{g} \text { uptake of } \\
\text { dye at initial } \\
\text { concentrations of } \\
\text { dye }(0.05,0.1 \text { and } \\
0.2 \mathrm{mg} / \mathrm{mL}) \\
\text { GO/PNIPAM: } \\
982,494 \text { and } 267 \\
\text { mg/g dye adsorbed } \\
\text { at concentrations of } \\
\text { dye }(0.05,0.1 \text { and } \\
0.2 \mathrm{mg} / \mathrm{mL})\end{array}$ & $\begin{array}{c}\text { Langmuir and } \\
\text { Pseudo-second order } \\
\text { kinetic model }\end{array}$ & [22] \\
\hline $\begin{array}{l}\text { Graphene oxide } \\
\text { intercalated } \\
\text { montmorillonite } \\
\text { nanocomposites }\end{array}$ & Crystal violet & $\begin{array}{c}\text { MtGO } \\
\text { nanocomposite: } \\
\text { Increase in } \\
\text { equilibrium } \\
\text { adsorption capacity } \\
\text { from } 184.67 \text { to } \\
583.08 \mathrm{mg} / \mathrm{g} \text { with } \\
\text { increasing dye } \\
\text { concentration } \\
\text { ranging from } 50 \text { to } \\
200 \mathrm{mg} / \mathrm{L} \text { within } 5 \\
\text { minutes of contact } \\
\text { time } \\
\end{array}$ & $\begin{array}{l}\text { Langmuir and } \\
\text { Pseudo-second order } \\
\text { kinetic model }\end{array}$ & [23] \\
\hline $\begin{array}{l}\text { Magnetic adsorbent } \\
\text { GO-APTS-poly(AMPS- } \\
\text { co-MA)/Fe3O4) }\end{array}$ & $\begin{array}{l}\text { Crystal violet } \\
\text { (CV) and } \\
\text { Methylene blue } \\
\text { (MB) }\end{array}$ & $\begin{array}{c}\text { Methylene blue = } \\
416.06 \mathrm{mg} / \mathrm{g} \text { Crystal } \\
\text { violet }=440.97 \\
\mathrm{mg} / \mathrm{g} . \text { with } 6 \mathrm{hrs} \text { of } \\
\text { contact time at pH } 6 \\
\text { and } 8\end{array}$ & $\begin{array}{c}\text { Chemisorption, } \\
\text { spontaneous, and } \\
\text { endothermic } \\
\text { Langmuir and } \\
\text { Pseudo-second order } \\
\text { kinetic model } \\
\end{array}$ & [24] \\
\hline $\begin{array}{l}\text { Nafion, Nafion-TiO2, } \\
\text { Nafion- GO, Nafion- } \\
\text { GOSULF }\end{array}$ & Methyl Orange & $\begin{array}{c}\text { Nafion }=47 \% \\
\text { Nafion-GO = } \\
46 \%\end{array}$ & $\begin{array}{c}\text { Langmuir and } \\
\text { Pseudo-second order } \\
\text { kinetic model }\end{array}$ & {$[25]$} \\
\hline
\end{tabular}


ICAASET-2021, 20-21 May, 2020, K.R. Mangalam University, Gurugram

International Journal of Technical Research \& Science (Special Issue) ISSN No.:2454-2024 (online)

\section{MECHANISM OF INTERACTION OF GRAPHENE OXIDE WITH ANIONIC AND CATIONIC DYES}

The most common mechanism for adsorption of dyes onto graphene oxide is either due to hydrogen bonding or $\pi-\pi$ interaction between adsorbate and adsorbent. Most of dyes either they are water soluble or insoluble are $\pi-$ electron rich as they have aromatic rings in their structure results in interaction with $\pi$-electrons of graphene oxide as shown in Fig. 5.1 and 5.2 [36]. Besides these interactions, there are some other factors also like hydrophobic effects due to aromatic rings of organic dyes and surface topology of graphene oxides and its derivatives and size of organic molecule which perform an essential part during adsorption of dyes [37].

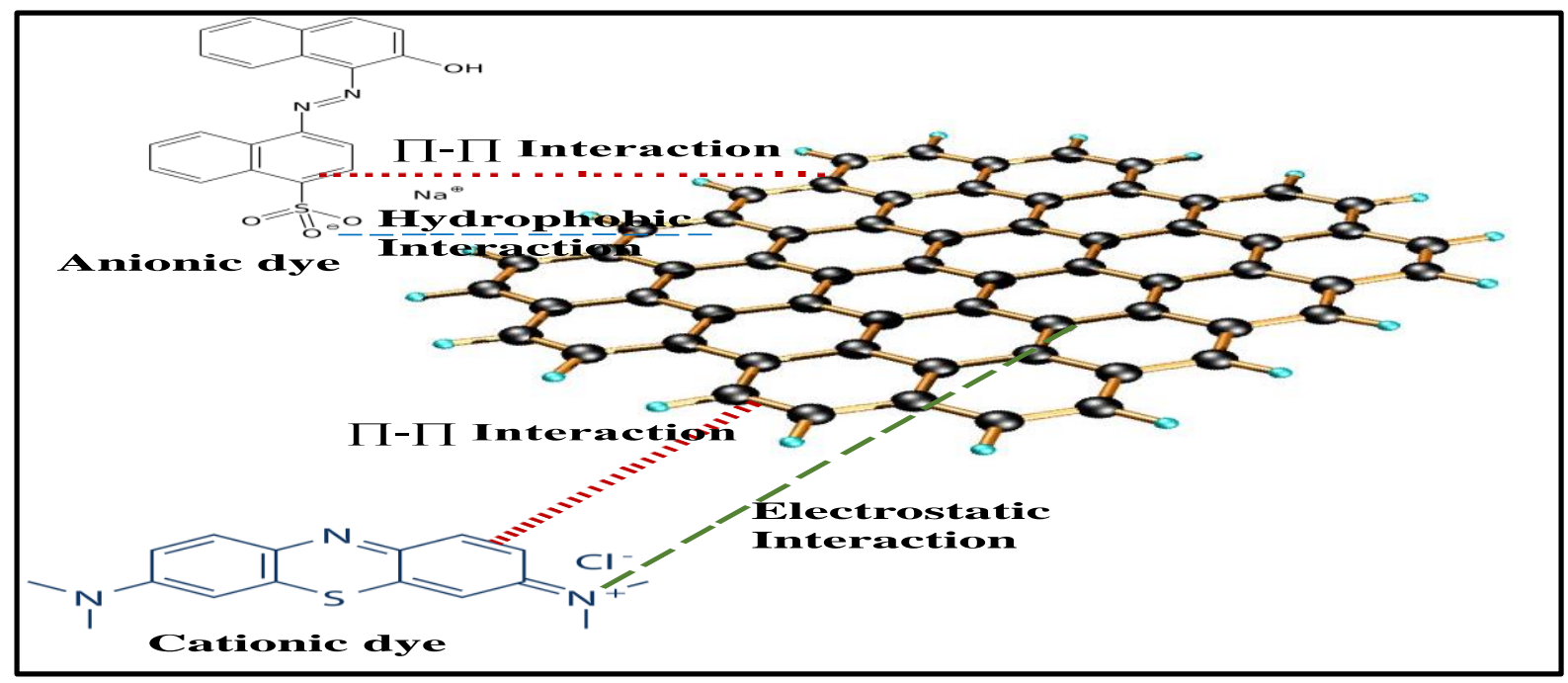

Fig. 5.1 Mechanism of interaction of cationic and anionic dyes with graphene oxide

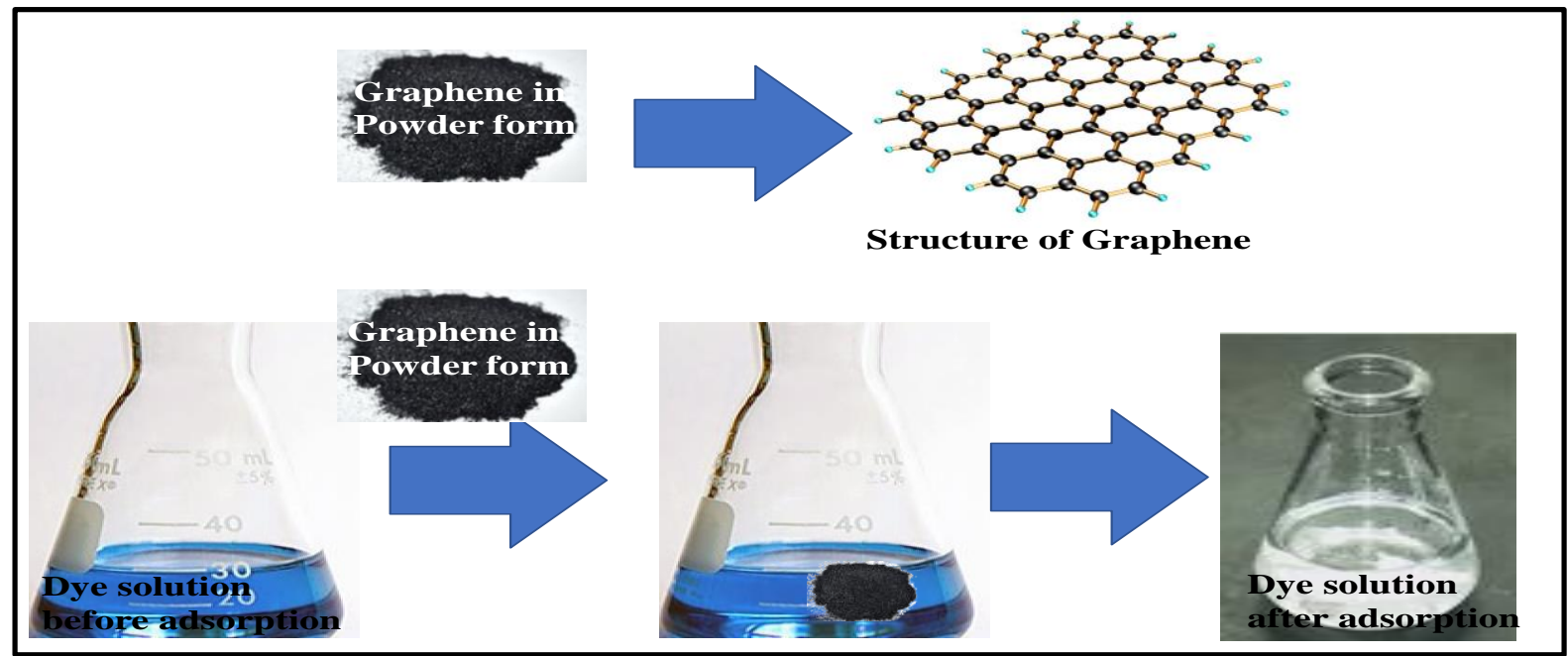

Fig. 5.2 Dye solution before and after adsorption onto graphene oxide adsorbent

\section{CONCLUSION}

The dyes used in textile and other different industries for coloring purposes are directly discarded into the environment which cause hazardous effect on human health as well as environment. Therefore, an effective treatment method is required to remove the effluents from waterbodies to avoid their deleterious effects on humans and aquatic organisms on their exposure. Attempts are being made to remove the dye effluents using graphene oxide and its derivatives due to their enhanced catalytic activities, high specific surface area and easy recovery. These composites removed the dyes either through adsorption process or free-radical mechanism, electrostatic and $\pi-\pi$ interactions. In the last, it is concluded that the removing efficiency can be enhanced by combining with other water purifying technologies so that the superior quality of water can be achieved.

\section{ACKNOWLEDGMENT}

The authors are thankful to the Director, K. R. Mangalam University, Gurugram for the valuable guidance.

\section{REFERENCES}

[1] Velusamy, S., Roy, A., Sundaram, S., Kumar, Mallick, T.: A Review on heavy metal ions and containing dyes removal through graphene oxide-based adsorption strategies for textile wastewater treatment. Chem Rec. (2021). 
ICAASET-2021, 20-21 May, 2020, K.R. Mangalam University, Gurugram

International Journal of Technical Research \& Science (Special Issue) ISSN No.:2454-2024 (online)

[2] Xu J., Cao Z., Zhang Y., Yuan Z., Lou Z., Xu X., Wang X.: A review of functionalized carbon nanotubes and graphene for heavy metal adsorption from water: Preparation, application, and mechanism. Chemosp. 195 (2018) 351-364.

[3] Gautam R. K., Chattopadhyaya, M. C. (Eds.). (2016). Advanced nanomaterials for wastewater remediation. CRC press.

[4] De Gisi S., Lofrano, G., Grassi, M., Notarnicola, M.: Characteristics and adsorption capacities of low-cost sorbents for wastewater treatment: a review. Sustain. Mater. Tech. 9 (2016) 10-40.

[5] Kant, A. Textile dyeing industry an environmental hazard, Nat. Sci. 04 (2012) 22-26.

[6] Moussavi, G., \&Mahmoudi, M.: Removal of azo and anthraquinone reactive dyes from industrial wastewaters using MgO nanoparticles. J. Hazard. Mater. 168 (2009) 806-812

[7] Rehman, A., Usman, M., Bokhari, T. H., ul Haq, A., Nisa, M. U.: The application of cationic-nonionic mixed micellar media for enhanced solubilization of Direct Brown 2 dye. J. Mol. Liquids 301 (2020) 112408.

[8] Ajmal, A., Majeed, I., Malik, R. N., Iqbal, M.: Photocatalytic degradation of textile dyes on $\mathrm{Cu}_{2} \mathrm{O}-\mathrm{CuO} / \mathrm{TiO}_{2}$ anatase powders. J. Environ. Chem. Engin. 4 (2016) 2138-2146

[9] Mao, B., Sidhureddy, B., Thiruppathi, A. R., Wood, P. C., Chen, C.:. Efficient dye removal and separation based on graphene oxide nanomaterials. New J. Chem. 44 (2020) 4519-4528

[10] Rahman, F. B.A., Akter M.: Removal of dyes form textile wastewater by adsorption using shrimp shell. Int. J. Waste Res. 6 (2016)

[11] Bhattacharjee, C., Dutta, S., Saxena, V. K.: A review on biosorptive removal of dyes and heavy metals from wastewater using watermelon rind as biosorbent. Environ. Adv. 2 (2020) 100007

[12] Khan, A., Wang, J., Li, J.: The role of graphene oxide and graphene oxide-based nanomaterials in the removal of pharmaceuticals from aqueous media: a review. Environ Sci Pollut Res. 24 (2017) 7938-7958

[13] Robati, D., Mirza, B., Rajabi, M., Moradi, O., Tyagi, I., Agarwal, S., Gupta, V.K.: Removal of hazardous dyes-BR 12 and methyl orange using graphene oxide as an adsorbent from aqueous phase. Chem. (2016)

[14] Sharma, P., Das, M.R.: Removal of a cationic dye from aqueous solution using graphene oxide nanosheets: investigation of adsorption parameters. J. Chem. Eng. Data 58 (2013) 151-158

[15] Cui, L., Guo, X., Wei, Q., Wang, Y., Gao, L., Yan, L., Yan, T., Du, B.: Removal of mercury and methylene blue from aqueous solution by xanthate functionalized magnetic graphene oxide: sorption kinetic and uptake mechanism. J. Colloid Interf. Sci. 439 (2015) 112-120

[16] Dong, Z., Wang, D., Liu, X., Pei, X., Chen, L., Jin, J.: Bio-inspired surface-functionalization of graphene oxide for the adsorption of organic dyes and heavy metal ions with a superhigh capacity. J. Mater. Chem. 2 (2014) 5034-5040.

[17] Chen, Y., Chen, L., Bai, H., \& Li, L.: Graphene oxide-chitosan composite hydrogels as broad-spectrum adsorbents for water purification. J. Mater. Chem. A 1 (2013) 1992-2001

[18] Zhang, X., Yu, H., Yang, H., Wan, Y., Hu, H., Zhai, Z., \& Qin, J.: Graphene oxide caged in cellulose microbeads for removal of malachite green dye from aqueous solution. J. Colloid Interf. Sci. 437 (2015) 277-282

[19] Sheng, G., Zhu, S., Wang, S., Wang, Z.: Removal of dyes by a novel fly ash-chitosan-graphene oxide composite adsorbent. RSC Adv.6 (2016) 17987-17994.

[20] Rong, X., Qiu, F., Qin, J., Zhao, H., Yan, J., \& Yang, D.: A facile hydrothermal synthesis, adsorption kinetics and isotherms to Congo Red azo-dye from aqueous solution of $\mathrm{NiO} /$ graphene nanosheets adsorbent. J. Indus. Engin. Chem. 26 (2016) 354-363

[21] Wan, Q., Liu, M., Xie, Y., Tian, J.: Facile and highly efficient fabrication of graphene oxide-based polymer nanocomposites through mussel-inspired chemistry and their environmental pollutant removal application. J. Mater. Sci. 52 (2016) 504-518

[22] Cao, M., Shen, Y., Yan, Z., Wei, Q.: Extraction-like removal of organic dyes from polluted water by the graphene oxide/PNIPAM composite system. Chem. Engin. J. 405 (2021) 126647.

[23] Puri, C., Sumana, G.: Highly effective adsorption of crystal violet dye from contaminated water using graphene oxide intercalated montmorillonite nanocomposite. App. Clay Sci. 166 (2018) 102-112

[24] Sahraei, R., Hemmati, K., Ghaemy, M.: Adsorptive removal of toxic metals and cationic dyes by magnetic adsorbent based on functionalized graphene oxide from water. RSC Adv. 6 (2016) 72487-72499.

[25] Filice, S., D’Angelo, D., Libertino, S., Nicotera, Scalese, S.: Graphene oxide and titania hybrid Nafion membranes for efficient removal of methyl orange dye from water. Carbon 82 (2015) 489-499.

[26] Wang, G., Li, G., Huan, Y., Hao, C., Chen, W.: Acrylic acid functionalized graphene oxide: high-efficient removal of cationic dyes from wastewater and exploration on adsorption mechanism. Chem. (2020) 127736.

[27] Nezhad, A. A., Alimoradi, M., Ramezani, M.: One-step preparation of graphene oxide/polypyrrole magnetic nanocomposite and its application in the removal of methylene blue dye from aqueous solution. Mater. Res. Exp. 5 (2018) 025508.

[28] Nuengmatcha, P., Mahachai, R., Chanthai, S.: Adsorption capacity of the as-synthetic graphene oxide for the removal of alizarin red S dye from aqueous solution. Orient. J. Chem. 32 (2016) 1399-1410.

[29] Hao, Y., Wang, Z., Gou, J., Dong, S.: Highly efficient adsorption and removal of Chrysoidine Y from aqueous solution by magnetic graphene oxide nanocomposite. Arab. J. Chem. (2015)

[30] Pervez, M. N., He, W., Zarra, T., Naddeo, V., Zhao, Y.: New sustainable approach for the production of $\mathrm{Fe}_{3} \mathrm{O}_{4}$ /graphene oxide-activated persulfate system for dye removal in real wastewater. Water 12 (2020) 733 
ICAASET-2021, 20-21 May, 2020, K.R. Mangalam University, Gurugram

International Journal of Technical Research \& Science (Special Issue) ISSN No.:2454-2024 (online)

[31] Aboelfetoh, E. F., Gemeay, A. H., El-Sharkawy, R. G.: Effective disposal of methylene blue using green immobilized silver nanoparticles on graphene oxide and reduced graphene oxide sheets through one-pot synthesis. Environ. Monit. Assess., 192 (2020)

[32] Xue, Z., Zhao, S., Zhao, Z., Li, P., Gao, J.: Thermodynamics of dye adsorption on electrochemically exfoliated graphene. J. Mater. Sci. 51 (2016) 4928-4941

[33] Bhattacharyya, A., Mondal, D., Roy, I., Sarkar, G.: Studies of the kinetics and mechanism of the removal process of proflavine dye through adsorption by graphene oxide. J. Mol. Liquids 230 (2017) 696-704

[34] Minitha, C. R., Lalitha, M., Jeyachanderen, Y. L., Senthilkumar. L., Kumar, R. T. R.: Adsorption behaviour of reduced graphene oxide towards cationic and anionic dyes: Co-action of electrostatic and $\pi-\pi$ interactions. Mater. Chem. Phy. 194 (2017) 243-252.

[35] Sahu, T. K., Arora, S., Banik, A., Iyer, P. K., Qureshi, M.: Efficient and rapid removal of environmental malignant arsenic(III) and industrial dyes using reusable, recoverable ternary iron oxide - ORMOSIL reduced graphene oxide composite. ACS Sustain. Chem. Engin. 5 (2017) 5912-5921

[36] Naeem, H., Ajmal, M., Muntha, S., Ambreen, J.: Synthesis and characterization of graphene oxide sheets integrated with gold nanoparticles and their applications to adsorptive removal and catalytic reduction of water contaminants. RSC Adv. 8 (2018) 3599-3610

[37] Lan Huong, P. T., Tu, T., Lan, H. Thang, H., Le, A. T.: Functional manganese ferrite/graphene oxide nanocomposites: effects of graphene oxide on the adsorption mechanisms of organic MB dye and inorganic $\operatorname{As}(\mathrm{V})$ ions from aqueous solution.

[38] RSC Adv. 8 (2018) 12376-12389. 